\title{
Políticas públicas de inovação no setor agropecuário: uma avaliação dos fundos setoriais*
}

\author{
José Eustáquio Ribeiro Vieira Filho
}

Instituto de Pesquisa Econômica Aplicada, Brasília (DF), Brasil

Recebido: 15/03/2012 Versão Revisada (entregue): 24/09/2012 Aprovado: 09/11/2012

\begin{abstract}
Resumo
O presente artigo avalia os fundos setoriais, em especial o CT-Agronegócio. Além de apresentar o sistema nacional de inovação agropecuária no Brasil, o trabalho mostra a dinâmica do fundo de desenvolvimento tecnológico relacionado à agricultura. Para tanto, é feita uma rápida descrição dos projetos relacionados à agricultura, que receberam suporte financeiro por meio de outros instrumentos, em especial as açóes transversais e os demais fundos setoriais. Os resultados indicam que o CT-Agronegócio é um mecanismo que transforma ciência básica em inovação tecnológica. Por fim, discute-se o fortalecimento das políticas de apoio à inovação.
\end{abstract}

Palavras-Chave | Mudança Tecnológica; Políticas Públicas; Pesquisa e Desenvolvimento

Códigos JEL | O13; O3; O38

* Além das contribuições dos avaliadores anônimos, o autor agradece aos colegas do Ipea que participaram do Projeto dos fundos setoriais e que contribuíram para o desenvolvimento dessa pesquisa, eximindo-os de qualquer erro ou omissão que possa aqui ocorrer. 


\title{
Public policies concerning technological innovation in agriculture: assessing the sectoral funds
}

\begin{abstract}
The aim of this paper is to analyze the sectoral funds directed to agribusiness (CT-Agribusiness). Besides presenting the national system of agricultural innovation in Brazil, the study shows the dynamic of technological development related to agribusiness sectoral funds. A description of the projects related to agriculture is presented, even if they received support from other instruments, particularly from other sectoral funds. Results show that the CT-Agribusiness converts basic science into technological innovation. Finally, different policies to promote technological innovation are discussed.
\end{abstract}

KEYWORDS | Technological Change; Public Policy; Research and Development

JEL-CODES | O13; O3; O38

\section{Introdução}

A interação entre a ciência e a tecnologia é bastante discutida no impacto gerado no aumento da produção. A constituição de um sistema nacional de inovações é extremamente importante para garantir o sucesso desta interação. O presente estudo tem por objetivo fazer uma avaliação das políticas de inovação tecnológica relacionadas ao desenvolvimento do setor agropecuário brasileiro.

Deve-se destacar que a inovação na agricultura depende de um arcabouço institucional capaz de gerar conhecimento público e oportunidades tecnológicas, bem como da capacidade dos agentes produtivos de acumular conhecimento. O Brasil é considerado um exemplo de excelência na produção de conhecimento aplicado à produção agropecuária. Além disso, dependendo da região e do tipo de cultivo, são bem-sucedidas as ações empreendidas pelos agentes produtivos em termos de aumento da capacidade de absorção do conhecimento externo. 
Nos últimos 50 anos, o Brasil deixou de ser um país agroexportador, diversificando sua pauta produtiva e elevando a participação da transformação industrial. Contudo, houve, simultaneamente, uma modernização da produção agropecuária, colocando o Brasil como agente central no cenário internacional. As estimativas da participação do agronegócio na economia brasileira variam de $15 \%$, num sentido mais estrito, até $45 \%$, englobando toda a organização da atividade agrícola. ${ }^{1}$

No que se refere ao planejamento estratégico de desenvolvimento nacional, a produção agropecuária relaciona-se a três grandes temáticas - segurança alimentar, matriz energética e sustentabilidade ambiental - que se inserem no debate do crescimento sustentável. Assim, o fornecimento de alimentos essenciais a custos competitivos, a diversificação da matriz energética com a inclusão cada vez maior do uso de biomassa e a incorporação da questão ambiental na dinâmica produtiva fazem parte de uma estratégia mais ampla de crescimento com incorporação tecnológica.

Procura-se, neste estudo, fazer uma avaliação dos projetos apoiados pelo Fundo Nacional de Desenvolvimento Científico e Tecnológico (FNDCT), em particular daqueles vinculados ao fomento do agronegócio brasileiro. Para tanto, cinco seçôes são apresentadas, contando com esta breve introdução. A segunda seção caracteriza o sistema nacional de inovação agroindustrial. A terceira mostra a participação dos fundos setoriais (em especial o CT-Agronegócio) no conjunto das despesas agrícolas. A quarta apresenta os resultados da avaliação amostral dos fundos setoriais, procurando verificar a interação entre a ciência e a tecnologia. Por fim, seguem-se as principais consideraçôes acerca da política de inovação destinada à promoção do agronegócio brasileiro, analisando o esforço público nessa direção.

\section{Sistema nacional de inovação agroindustrial}

A organização da atividade agrícola é definida em sentido amplo, envolvendo não apenas as atividades a montante e a jusante da unidade produtiva, mas também um amplo sistema de pesquisa, ciência e tecnologia (Figura 1). As inovações relevantes na agricultura ocorrem ao longo da cadeia produtiva regional. ${ }^{2}$

1 Gasques et al. (2004) mensuraram a participação do agronegócio em torno de 34\% do Produto Interno Bruto (PIB) brasileiro, sendo este dividido, em média, por $6 \%$ pelos insumos agropecuários, 30\% pela agropecuária, 31\% pela agroindústria e 33\% pela distribuição.

2 Para uma melhor compreensão deste conceito, ver Possas, Salles-Filho e Silveira (1996), Vieira Filho (2004), Vieira Filho, Campos e Ferreira (2005) e Vieira Filho (2009). 
FIGURA 1

Inovação, ciência e tecnoloqia na orqanização da atividade aqrícola

\section{ORGANIZAÇÃO DA ATIVIDADE AGRÍCOLA}

SETOR FORNECEDOR

UNIDADE PRODUTIVA

DISTRIBUIÇÃO

\begin{tabular}{|c|c|c|c|}
\hline $\begin{array}{l}\text { Mecânica } \\
\text { Máquinas } \\
\text { Implementos } \\
\text { Equipamentos de Irrigação } \\
\text { Aviação Agricola } \\
\text { Química } \\
\text { Fertilizantes } \\
\text { Defensivos } \\
\text { Biológica } \\
\text { Sementes } \\
\text { Microorganismos } \\
\text { Controle Biológico } \\
\text { Melhoramento Genético } \\
\text { Transgênicos }\end{array}$ & $\longleftrightarrow \begin{array}{l}\text { Agronômicas } \\
\text { Preparo do Solo } \\
\text { Conservação do Solo } \\
\text { Práticas Culturais } \\
\text { Adaptação de Cultivares } \\
\text { Épocas de Plantio } \\
\text { Colheita } \\
\text { Pré-processamento } \\
\text { Sistema de Produção Ani }\end{array}$ & $\longleftrightarrow$ & $\begin{array}{l}\text { Agroindustrial } \\
\text { Tecnologia Pós-colheita } \\
\text { Processamento } \\
\text { Logística } \\
\text { Especialização } \\
\text { Agregação de Valor } \\
\text { Organizacional } \\
\text { Gestão } \\
\text { Cooperativas } \\
\text { Mercados } \\
\text { Comercialização } \\
\text { Transporte } \\
\text { Armazenagem }\end{array}$ \\
\hline$\uparrow$ & & & $\uparrow$ \\
\hline $\begin{array}{l}\text { Pesquisa e desenvolvimento } \\
\text { público e privado }\end{array}$ & Extensão rural & & $\begin{array}{c}\text { Demanda por regulação } \\
\text { (qualidade, biossegurança } \\
\text { e rastreabilidade) }\end{array}$ \\
\hline
\end{tabular}

Fonte: Vieira Filho (2009).

O segmento fornecedor de insumos tecnológicos compreende as inovações mecânicas, químicas e biológicas. A distribuição incorpora as inovações agroindustriais e organizacionais, passando pelo armazenamento e processamento. Já a unidade de produção, centralizadora das principais demandas, gera as inovações agronômicas e gerenciais, além de sinalizar ao mercado oportunidades tecnológicas, promovendo e ampliando a troca de conhecimento.

O processo de adoção e difusão tecnológica depende do regime tecnológico ${ }^{3}$ e das redes de aprendizado no interior de toda organização produtiva. Nesse sentido, o ambiente institucional tem a capacidade de definir os paradigmas e as trajetórias

3 Conforme Malerba e Orsenigo (1996) e Breschi, Malerba e Orsenigo (2000), a tecnologia associa-se ao regime tecnológico, o qual define os padrões inovativos segundo as condições de oportunidade, de apropriabilidade, de cumulatividade e da natureza de transmissão do conhecimento. As oportunidades tecnológicas relacionam-se ao potencial inovativo de cada tecnologia e aumentam conforme o crescimento dos investimentos em P\&D. A apropriabilidade diz respeito ao grau de proteção das inovações contra as imitações. A cumulatividade é a capacidade de inovar baseada nas inovações passadas e nas áreas correlatas do conhecimento. Por fim, o conhecimento tecnológico é definido segundo seu grau de especificidade, de codificação e de complexidade. O conhecimento específico é codificado e, portanto, voltado às aplicações industriais. Quando o conhecimento for generalizado, o mesmo pode ser aplicado em diferentes domínios de pesquisa científica. Quando codificado, a transmissão do conhecimento se processa de forma mais ágil. Quando tácito, a difusão do novo conhecimento é realizada de forma mais lenta. 
tecnológicas, ${ }^{4}$ bem como propiciar maior conexão entre os agentes e facilitar a difusão do conhecimento.

No Brasil, a criação da Empresa Brasileira de Pesquisa Agropecuária (Embrapa), em 1973, é uma importante iniciativa na promoção do desenvolvimento tecnológico agrícola. A principal função da pesquisa pública na agricultura é a de viabilizar soluções para o desenvolvimento sustentável por meio da geração, da adaptação e da transferência de conhecimentos e de tecnologias ao setor produtivo.

Em 1992, o governo brasileiro instituiu o Sistema Nacional de Pesquisa Agropecuária (SNPA). ${ }^{5}$ Tal sistema é constituído pela Embrapa e suas unidades, pelas Organizações Estaduais de Pesquisa Agropecuária (OEPAs), por universidades e institutos de pesquisa de âmbito federal ou estadual, bem como por outras organizações, públicas e privadas, direta ou indiretamente vinculadas à atividade de pesquisa agropecuária.

O objetivo do SNPA é compatibilizar as diretrizes e estratégias da pesquisa agropecuária com as políticas de desenvolvimento. Além disso, procura-se assegurar a organização e a coordenação da matriz institucional dentro do setor, visando eliminar a dispersão de esforços, as sobreposições e a ineficiência alocativa dos recursos. Dentro deste sistema, tem-se o planejamento nacional de pesquisa, o qual fomenta a parceria entre as várias instituições no desenvolvimento da ciência e da tecnologia. Este esforço procura atender às demandas regionais de pesquisa, a fim de proporcionar melhor suporte ao desenvolvimento da agropecuária.

Para uma ideia do arcabouço institucional envolvido, o Quadro 1 apresenta a distribuição regional das OEPAs, que associam as demandas regionais ao interesse nacional. Estas organizações são compostas por 21 entidades. Vale lembrar que, dos 26 estados brasileiros, 16 possuem instituições de pesquisa agropecuária, concentradas na sua maioria nas regiōes Centro-Oeste, Sudeste e Sul. São quase 1.800 pesquisadores que realizam 2.100 projetos de pesquisa e desenvolvimento, nos seus 230 laboratórios e 215 estações experimentais. Num país continental como o Brasil, as especificidades regionais definem estratégias diferenciadas de pesquisa para cada macrorregião do país.

4 Estes conceitos procuram captar a ideia, segundo Dosi (1982 e 1984), de que as tecnologias diferem entre si por meio de um desenvolvimento baseado numa lógica interna forte e autônoma.

5 O SNPA foi instituído em 1992 pela Portaria de n. 193, de 07/08/1992, do Ministério da Agricultura, Pecuária e Abastecimento (Mapa), autorizado pela Lei Agrícola (Lei n. 8.171, de 17/01/1991). 
QUADRO 1

Organizações Estaduais de Pesquisa Agropecuária (OEPAs), segundo grandes regiões brasileiras

\begin{tabular}{lllll}
\hline $\begin{array}{c}\text { Regiões Norte e } \\
\text { Centro-Oeste }\end{array}$ & Região Nordeste & Região Sudeste & Região Sul \\
\hline Agência Rural & EBDA & Apta & Epagri \\
Empaer-MT & Emdagro & Epamig & Fepagro \\
Idaterra-MS & Emepa & Incaper & lapar \\
Unitins & Emparn & Pesagro-Rio & \\
& IPA & & \\
\hline
\end{tabular}

Fonte: Embrapa (2009).

O Gráfico 1 mostra a distribuição das instituições de ensino superior ligadas ao SNPA. De um total de 144 instituições, têm-se 38 federais, 32 estaduais e municipais, 42 privadas e 32 comunitárias, sendo que 62 possuem projetos de pesquisas relacionados às ciências agrárias. Nota-se que há uma concentração regional no Sudeste e no Sul. Em relação às instituições federais e estaduais, há um esforço público em atingir todas as regiões, mesmo que em uma menor escala no Centro-Oeste e no Norte. Vale destacar que no Sul o número de instituições estaduais supera o das federais. Quanto à rede privada de ensino, o Sudeste engloba 74\% das instituiçôes, enquanto as demais regiōes são pouco representativas.

A agricultura sempre teve papel central no desenvolvimento do país. Por intermédio da Embrapa, buscou-se desenvolver uma agricultura forte e apoiada na inovação tecnológica. É inegável o sucesso alcançado por esta iniciativa. Conforme mostra o Gráfico 2, de acordo com o balanço social da Embrapa, as tecnologias desenvolvidas e transferidas à sociedade cresceram drasticamente entre 1997 e 2008, o que estimulou e aumentou o retorno social para toda a economia. Isto representa melhorias nas condiçóes produtivas e nos aumentos de renda para os agricultores.

Para uma avaliação da capacidade inovativa do setor fornecedor de insumos tecnológicos na agricultura, calculou-se o quociente setorial ${ }^{6}$ (Gráfico 3), um indicador que mensura se o segmento em análise é mais inovativo do que o conjunto da economia. Se o valor do quociente for superior a 1 , há indício de que o segmento

6 De forma algébrica, o quociente setorial (QS) para um setor j em um produto ou grupo de produtos i pode ser definido da seguinte forma: $Q S_{i j}=\left(X_{i j} / X_{i z}\right) / ;\left(X_{j} / X_{z}\right)$; onde: $X_{i j}$ é o número de empresas inovadoras no insumo tecnológico i do setor fornecedor $\mathrm{j}, X_{i z}$ corresponde ao número total de empresas no insumo tecnológico i da zona de referência $z, X_{j}$ é o total de empresas inovadoras do setor fornecedor j e $X_{z}$ refere-se ao total de empresas da zona de referência z. Para outros indicadores de concentração e especialização, ver Haddad (1989). 
fornecedor do insumo tecnológico é relativamente mais importante, no contexto nacional, em termos gerais do resto da economia. Caso contrário, se o quociente for inferior a 1, o segmento fornecedor do insumo tecnológico é relativamente menos importante em relação ao agregado econômico. ${ }^{7}$

\section{GRÁFICO 1}

Instituições de ensino superior ligadas ao Sistema Nacional de Pesquisa Agropecuária (SNPA), por dependência administrativa, segundo grandes regiões brasileiras 2009

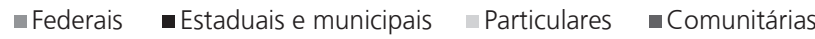

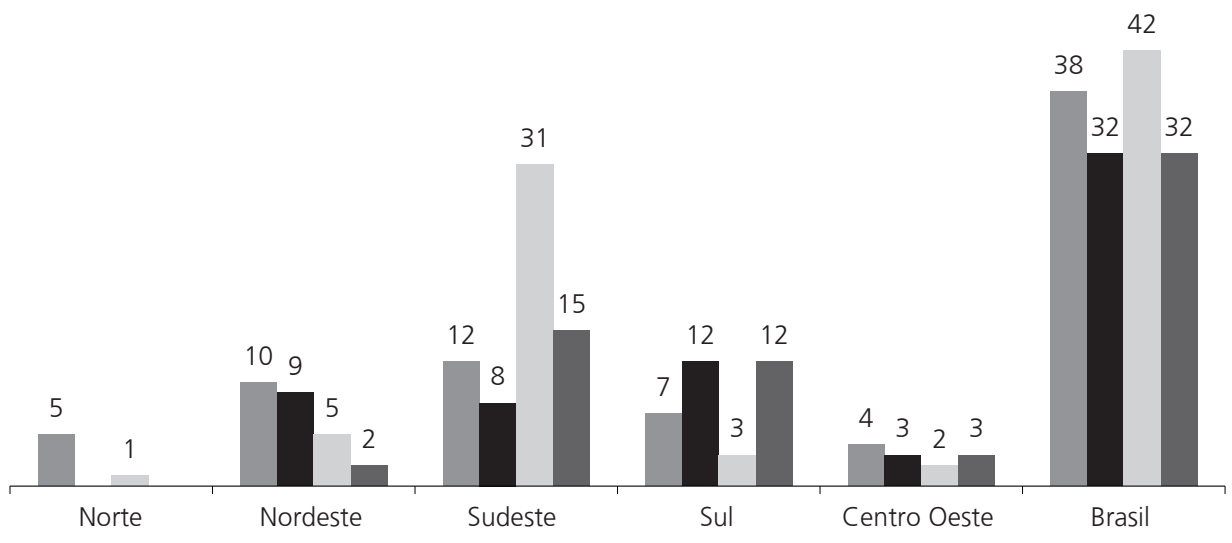

Fonte: Embrapa (2009).

7 Esta análise foi calculada para os anos de 2000, 2003 e 2005 com dados fornecidos pela Pintec, que possui duas referências temporais. A primeira, que engloba a maioria das variáveis qualitativas, refere-se a um período de três anos consecutivos, anteriores à coleta dos dados. Por exemplo, as inovações de produto e/ou processo correspondem àquelas implementadas nesses três anos. A segunda, que mensura as variáveis quantitativas (gastos e pessoal ocupado em P\&D, impacto da inovação de produto sobre as vendas e as exportações, etc.) e algumas variáveis qualitativas (patentes em vigor, por exemplo), refere-se ao último ano do período de referência da pesquisa, ou seja, o ano de referência. Portanto, o período coberto pelo cálculo do quociente é mais amplo do que o ano de referência apenas, de acordo com a metodologia da Pintec. Infelizmente, o nível de desagregação necessário para calcular o indicador para 2008 não foi mais fornecido pelo IBGE. Por esse motivo, não se utilizou a última Pintec. 


\section{GRÁFICO 2}

Receita operacional líquida e tecnologias desenvolvidas e transferidas à sociedade pela Embrapa

1997-2008

Receita Operacional Líquida (RL) —Tecnologias Desenvolvidas e Transferias à Sociedade — Retorno

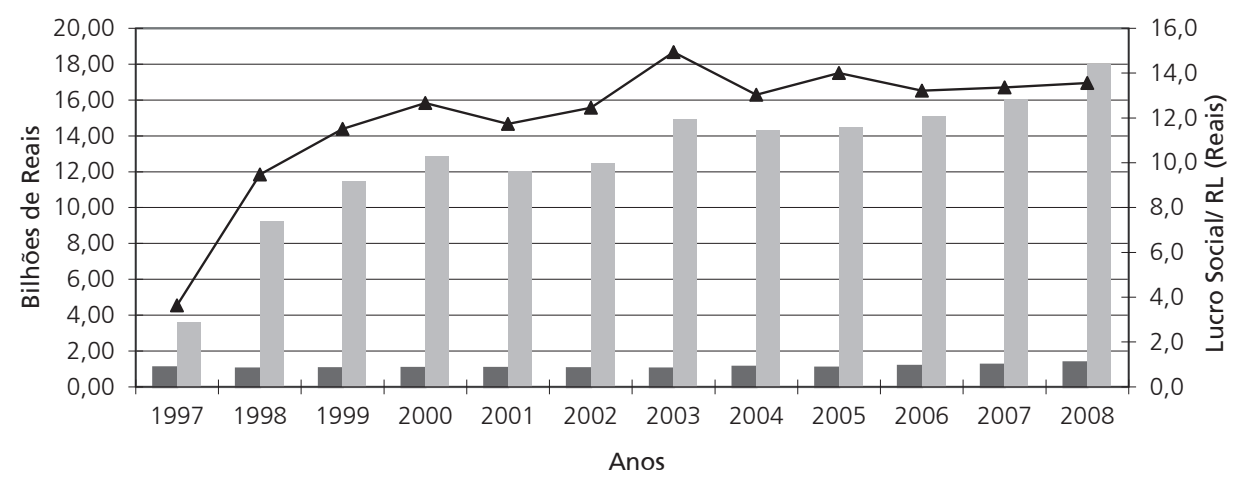

Fonte: Embrapa (2009).

Com base no entendimento dos resultados do quociente setorial, verificou-se que o setor agrícola (incluindo o setor fornecedor de insumos tecnológicos, a produção de biocombustível e a indústria de transformação de alimentos) é relativamente mais importante do que o resto da economia brasileira, o que identifica a importância do agronegócio como propulsor de inovações tecnológicas e de novos conhecimentos. As exceções relacionam-se ao calcário e à indústria extrativa mineral, esta última apenas no ano de 2003. Portanto, quando comparada ao conjunto da economia nacional, a cadeia produtiva regional relacionada ao agronegócio é relativamente mais importante em termos de inovaçôes tecnológicas.

Entretanto, é necessário ressaltar que, embora o setor fornecedor de insumos tecnológicos tenha boa capacidade relativa de inovar, a economia brasileira depende de parte das importaçóes dos insumos. Quando se analisa a balança comercial dos insumos tecnológicos da produção agropecuária, percebe-se claramente a dependência brasileira em termos das importaçôes de defensivos, medicamentos veterinários e fertilizantes (Gráfico 4). Vale ressaltar que, diante de um marco regulatório nacional cada vez mais exigente com a entrada de novos competidores e produtos, seja por questões sanitárias ou ambientais, a produção de insumos se concentra em poucas empresas e alguns produtos, o que eleva o custo de adoção 
destas tecnologias, bem como deixa vulnerável o crescimento da produtividade do setor como um todo.

\section{GRÁFICO 3}

Quociente setorial das empresas inovadoras

Brasil - 2000-2005

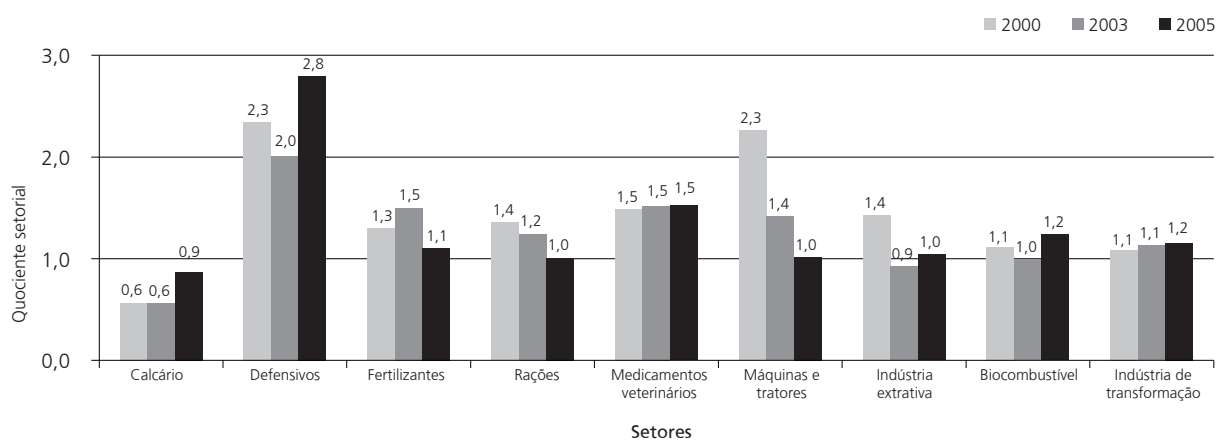

Fonte: IBGE. Pesquisa de Inovação Tecnológica - Pintec. Elaboração do autor.

\section{GRÁFICO 4}

Saldo comercial dos principais insumos tecnológicos do setor agropecuário Brasil - 1997-2007
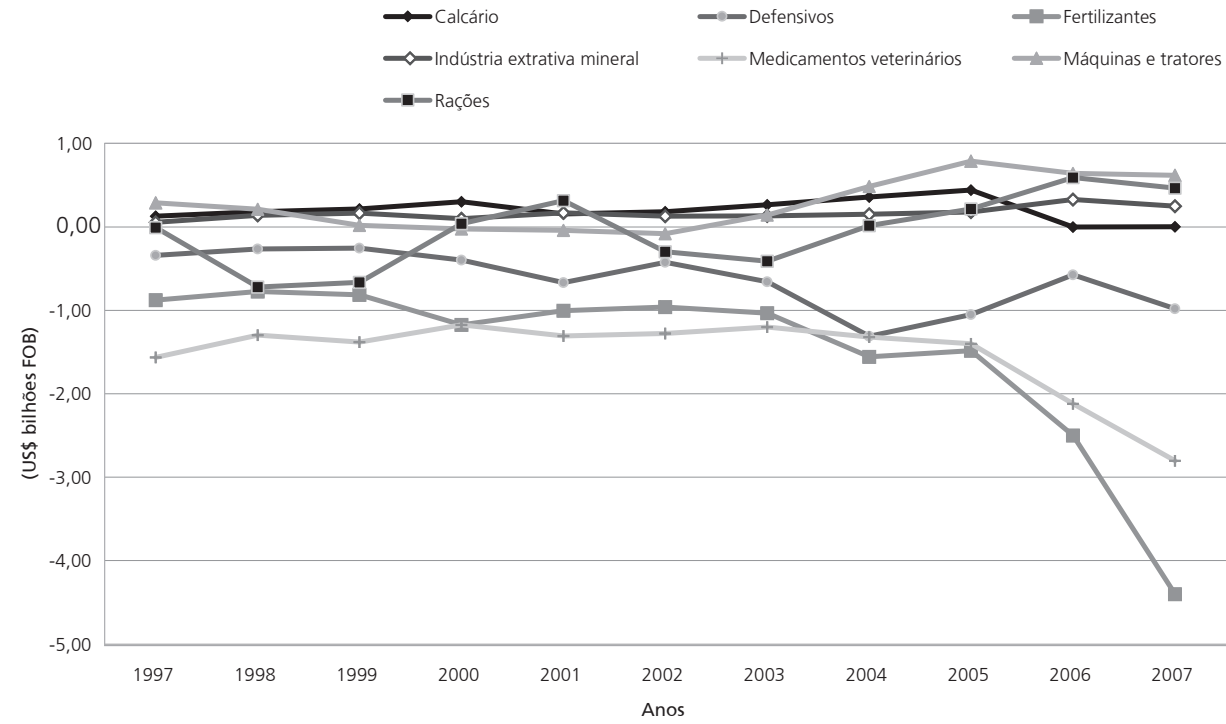

Fonte: Sistema Alice da Secretaria de Comércio Exterior - Secex. Elaboração do autor. 
Diante do exposto, o SNPA tem papel central na condução do desenvolvimento agropecuário brasileiro. Por um lado, é nítido o sucesso na construção de um ambiente institucional, o qual facilita a adoção e a difusão das melhores tecnologias e práticas entre os agentes produtivos. Por outro, no tocante à natureza do setor fornecedor, cabe ao SNPA pensar estratégias de desenvolvimento tecnológico no âmbito doméstico, numa tentativa explícita de reduzir o grau de dependência da economia externa. De qualquer forma, as políticas adotadas ao longo das últimas quatro décadas propiciaram um avanço significativo da modernização agropecuária. Em lugar do país agroexportador da década de 1950, em que existia a importação líquida de vários alimentos, o Brasil tornou-se uma potência agropecuária com a capacidade de ofertar parcela significativa de produtos agropecuários para o mundo.

\section{A representatividade dos fundos setoriais e os recursos destinados ao setor agropecuário}

A inovação tecnológica não resulta de uma ação individual. Pelo contrário, para que haja o surgimento de novas técnicas e conhecimentos, é preciso uma maior coordenação entre instituiçôes financeiras com crédito subsidiado, indústria fornecedora de insumos estratégicos, universidades e institutos de pesquisa, que possam ampliar a ciência básica e estimular a ciência aplicada.

A criação dos fundos setoriais, a partir de 1999, visou incentivar o desenvolvimento científico e tecnológico em áreas estratégicas, além de construir um novo mecanismo de financiamento de investimentos. Pretendeu-se financiar, prioritariamente, o fomento tecnológico, os projetos cooperativos, as redes de pesquisas e os projetos estruturantes. Este mecanismo garantiu a vinculação de recursos públicos necessários à continuidade das políticas de ciência e tecnologia.

Esta seção visa apresentar o quadro de apoio financeiro do governo brasileiro à inovação tecnológica, em especial à produção agropecuária. $\mathrm{O}$ agronegócio é responsável por uma parcela significativa do produto nacional. O fundo setorial destinado ao fomento do setor agropecuário é o CT-Agronegócio, criado em 2001. ${ }^{8}$ Seu objetivo é promover a capacitação científica e tecnológica nas áreas de agronomia, veterinária, biotecnologia, economia e sociologia agrícola, entre outras áreas

8 O CT-Agronegócio foi criado pela Lei n. 10.332, de 19/12/2001, e regulamentado pelo Decreto n. 4.157, de 12/03/2002. Nesse sentido, embora a constituição dos fundos setoriais seja de 1999, a base de dados aqui estudada tem sua série histórica iniciada em 2002. 
correlatas. Além disso, busca-se uma atualização tecnológica do setor como um todo, estimulando a ampliação dos investimentos na área de biotecnologia agrícola tropical e na difusão de novas tecnologias.

Para exercer este objetivo, o CT-Agronegócio tem como fonte de financiamento o valor de $17,5 \%$ do total da Contribuição de Intervenção no Domínio Econômico (Cide), ${ }^{9}$ cuja arrecadação advém da incidência de alíquota de $10 \%$ sobre a remessa de recursos ao exterior para pagamento de assistência técnica, royalties, serviços técnicos especializados ou profissionais. A utilização desses recursos observa os critérios de administração previstos, bem como a programação orçamentária do Fundo Nacional de Desenvolvimento Científico e Tecnológico (FNDCT). ${ }^{10}$ Vale ressaltar que, por meio de uma política de desenvolvimento regional, a legislação prevê o destino de $30 \%$ dos recursos do CT-Agronegócio para o financiamento de projetos locados nas Regiōes Norte, Nordeste e Centro-Oeste.

Ao comparar a arrecadação e o empenho do CT-Agronegócio no total da arrecadação e do empenho dos fundos setoriais (Gráfico 5), nota-se que o percentual empenhado ultrapassa o arrecadado já em 2004. Isto significa dizer que, quanto maior o percentual de empenho, menor será o contingenciamento dos recursos, o que identifica uma dinâmica favorável à liberação dos recursos do CT-Agronegócio em contraposição aos demais fundos. O percentual arrecadado pelo CTAgronegócio varia de 4\% a 5\% entre 2002 e 2009. No que tange ao empenho do CT-Agronegócio, o percentual que era inferior a 1\%, em 2002, passa para valores próximos de 6\% em 2009.

O Gráfico 6 mostra um comparativo dos recursos destinados ao CT-Agronegócio em relação ao gasto total do Brasil com o setor agrícola. Entre 2002 e 2008, o valor arrecadado pelo CT-Agronegócio não ultrapassou 1\% do que se gasta com o setor agropecuário. De qualquer forma, o recurso empenhado aumentou ao longo do tempo, chegando em 2008 num valor próximo de 0,6\%. O diferencial entre o arrecadado e o empenhado, como consequência, reduziu-se ao longo do tempo.

Sabendo que a Embrapa exerce papel fundamental no desenvolvimento de tecnologias voltadas ao agronegócio, considerou-se oportuno fazer um comparativo dos valores arrecadados e empenhados em relação à receita operacional líquida desta empresa (Gráfico 7). Observou-se que o valor arrecadado pelo CT-Agronegócio fica em torno de 6\%, num limite inferior, e de 8,5\%, num limite

9 A Cide foi instituída pela Lei n. 10.168, de 29/12/2000, e alterada pela Lei n. 10.332, de 19/12/2001.

10 O FNDCT foi instituído pelo Decreto-Lei n. 719, de 31/07/1969, e restabelecido pela Lei n. 8.172, de 18/01/1991. 
superior. Quando o quadro comparativo se faz em relação à Embrapa, verificou-se que o montante destinado à arrecadação é algo significativo. No que tange ao percentual empenhado, este elevou-se ao longo do período, atingindo um patamar de $6 \%$ ao final de 2008.

\section{GRÁFICO 5}

Participação do fundo CT-Agronegócio na arrecadação e no empenho totais dos fundos setoriais

Brasil - 2002-2009

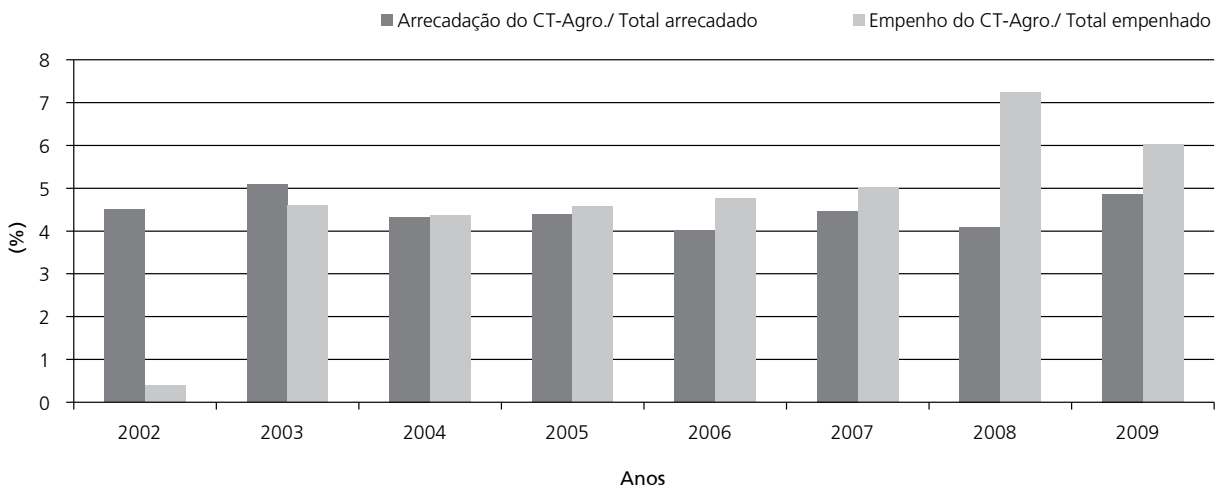

Fonte: Ministério da Ciência e Tecnologia (2009). Elaboração do autor.

GRÁFICO 6

Comparativo da participação do fundo CT-Agronegócio em relação ao gasto total no setor agrícola

Brasil - 2002-2008

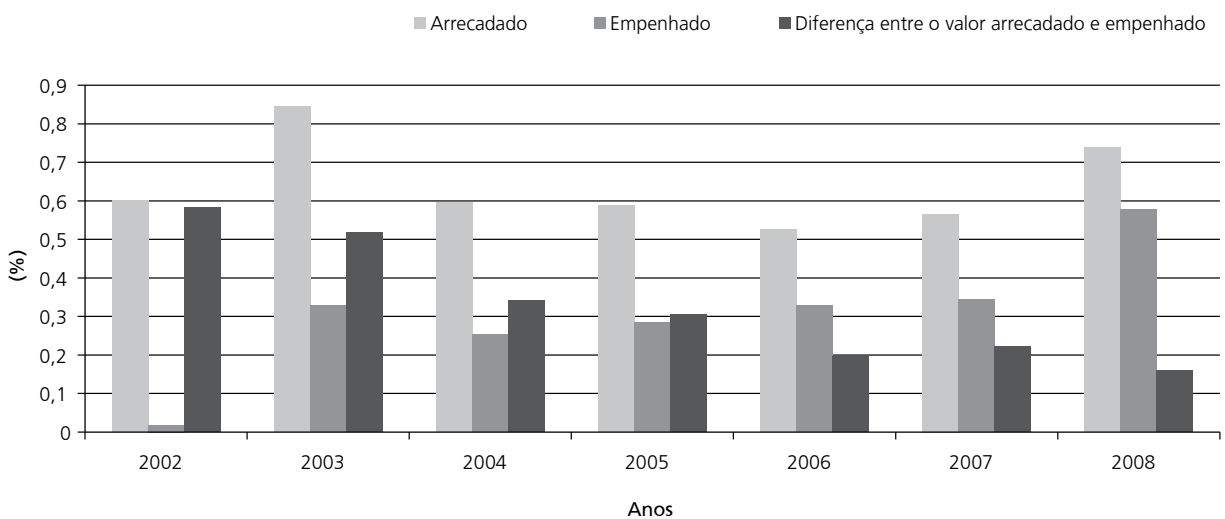

Fonte: Ministério da Ciência e Tecnologia (2009). Elaboração do autor. 


\section{GRÁFICO 7}

Comparativo da participação do fundo CT-Agronegócio em relação

à Receita Operacional Líquida da Embrapa

2002-2009

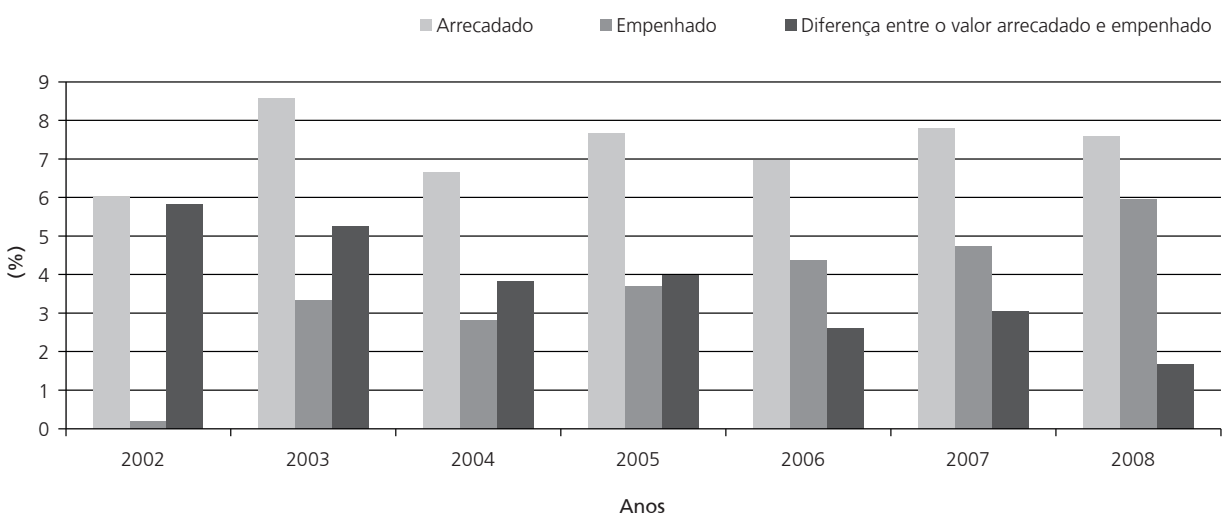

Fonte: Ministério da Ciência e Tecnologia (2009). Elaboração do autor.

De um lado, o avanço institucional do CT-Agronegócio definiu a garantia da vinculação de recursos públicos ao fomento de políticas de inovação em ciência e tecnologia para o setor agropecuário. De outro, este mecanismo de inovação propiciou mais um elemento de incentivo à pesquisa aplicada, complementar aos gastos realizados no conjunto da agricultura. Porém, é preciso ressaltar que, isoladamente, o fundo é pouco expressivo, mas constitui uma clara sinalização do governo para a questão da inovação no agronegócio.

\section{Uma análise amostral do CT-Agronegócio e a relação entre ciência e tecnologia}

O objetivo desta seção é analisar, num panorama amostral, a participação relativa dos recursos destinados ao agronegócio, inclusive aos projetos oriundos do financiamento agregado de todos os fundos setoriais. Além disso, procurou-se verificar de que forma a execução destes projetos está vinculada, numa tentativa de compreender a relação entre universidades e institutos de pesquisas com as empresas.

Para uma compreensão mais ampla do CT-Agronegócio, a Tabela 1 apresenta a distribuição dos projetos e valores contratados, segundo os fundos setoriais. De 2000 a 2008, foram financiados mais de 13 mil projetos com um montante de 5,3 bilhões de reais (a preços de 2008), sendo estes repartidos em 21 fundos diferentes. 
$\mathrm{Na}$ ordem de relevância dos valores contratados, destacaram-se as linhas horizontais de financiamento nas três primeiras posiçōes (CT-Transversal, CT-Infraestrutura e Subvenção Econômica). As Ações Transversais foram definidas em 2004, pelo Comitê de Coordenação dos Fundos Setoriais, como sendo programas estratégicos do Ministério da Ciência e Tecnologia que têm ênfase na Política Industrial, Tecnológica e de Comércio Exterior (PITCE) do governo federal e que utilizam recursos de diversos fundos setoriais simultaneamente.

No caso específico do CT-Transversal, decidiu-se que cada fundo contribuiria com $50 \%$ dos seus recursos para essas Ações. Tal fundo representou quase a metade do número de projetos $(43,6 \%)$ e mais de um quarto do valor contratado (26,3\%). O CT-Infraestrutura ( $6 \%$ dos projetos totais e $18,8 \%$ do valor contratado) é financiado por meio de $20 \%$ dos recursos destinados a cada Fundo de Apoio ao Desenvolvimento Científico e Tecnológico. A Subvenção Econômica, regulamentada pela Lei do Bem e Lei da Inovação (2005 e 2006, respectivamente), tem caráter também horizontal, mas é um financiamento específico para as empresas. A Subvenção participou com $2,5 \%$ dos projetos totais; entretanto, em valor contratado, representou uma fatia nada desprezível de 14,9\%. Quanto ao CT-Agronegócio, o mesmo aparece somente na $12^{a}$ posição por valor contratado. Foram 683 projetos (5,1\% do total) com financiamento de 105 milhōes de reais (cerca de $2 \%$ dos fundos setoriais). Nota-se que o valor médio por projeto do CT-Agronegócio é $60 \%$ inferior à média observada pelo valor médio por projeto dos fundos setoriais (ver a última coluna da Tabela 1).

No intuito de aprofundar as análises no impacto dos fundos setoriais no agronegócio brasileiro, foram feitas tabulações especiais (valores contratados por projetos), no sentido de comparar o CT-Agronegócio, o CT-Transversal relacionado ao agronegócio e o total dos fundos setoriais. Esta análise procurou separar as instituiçôes ligadas ao SNPA, de um lado, e relacionar os projetos por palavras-chave associadas às pesquisas voltadas ao agronegócio. Para dimensionar o CT-Transversal relacionado ao agronegócio, foi preciso buscar os projetos via as palavras-chave. 


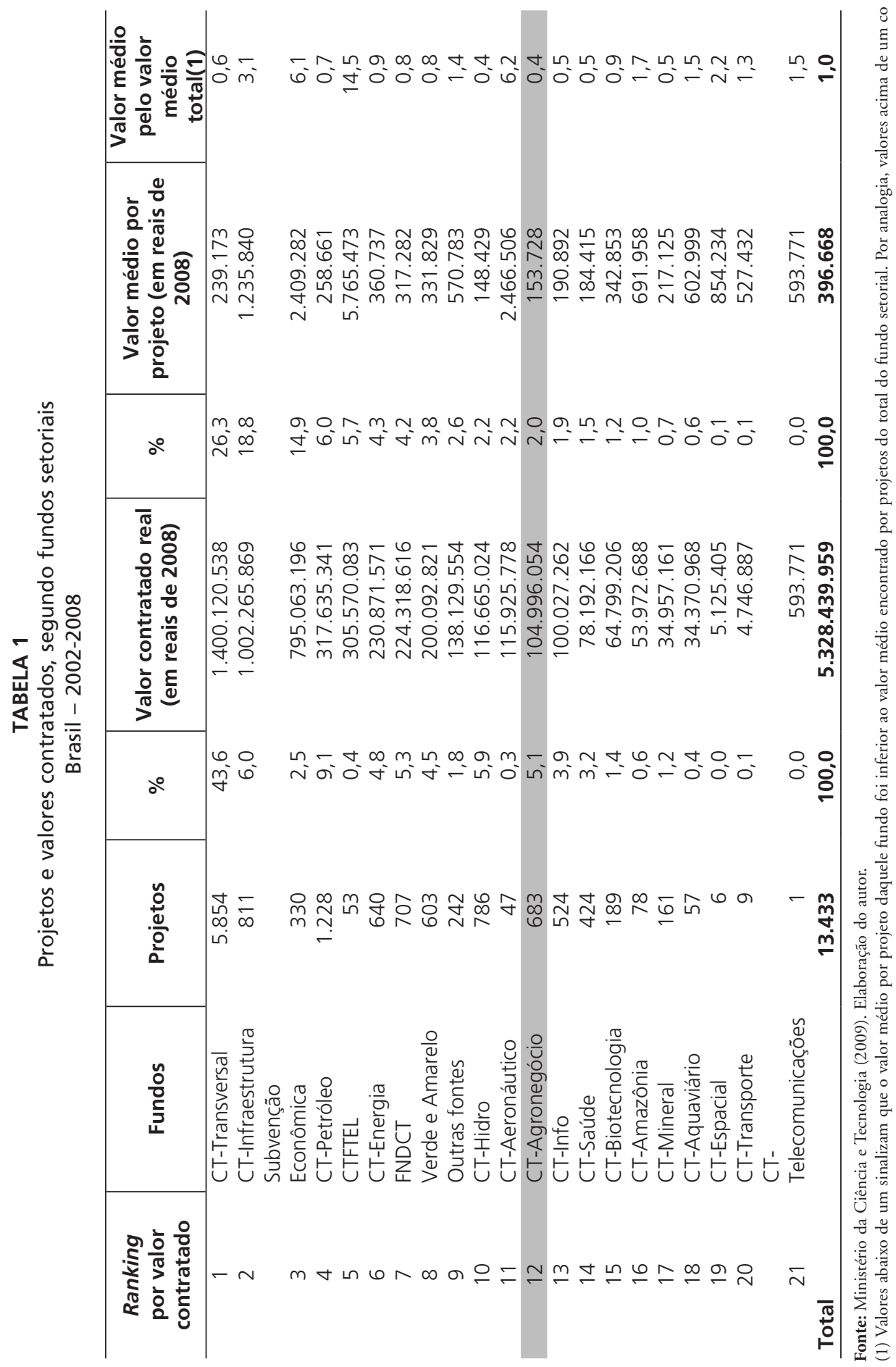


A Tabela 2 mostra os valores correntes contratados por projetos de Instituições ligadas ao SNPA. Observa-se que o CT-Transversal, no total agrícola, supera o montante de recursos destinados ao CT-Agronegócio, o que significa que o agronegócio foi priorizado no conjunto das Ações Transversais em detrimento dos demais fundos. Entretanto, quando analisadas a Embrapa, a Escola Superior de Agricultura Luiz de Queiroz da Universidade de São Paulo (Esalq-USP) e a Universidade Federal de Viçosa (UFV), verifica-se que os recursos destinados ao CT-Agronegócio são superiores às Ações Transversais, pois são instituições financiadas diretamente pelo CT-Agronegócio.

O Gráfico 8 mostra o percentual médio anual do valor contratado de todos os fundos setoriais por instituições ligadas ao SNPA, no período 2002-2008. O total dos recursos contratados que se relacionaram ao setor agropecuário ficou em torno de $6,9 \%$, sendo que, deste total, $42 \%$ corresponderam à Esalq-USP, $12 \%$ à Embrapa, $7 \%$ às OEPAs e $6 \%$ à UFV, 6\%.

\section{GRÁFICO 8}

Percentual anual médio do valor contratado por instituições ligadas ao SNPA no valor total dos fundos setoriais 2002-2008

$\mathrm{Em} \%$

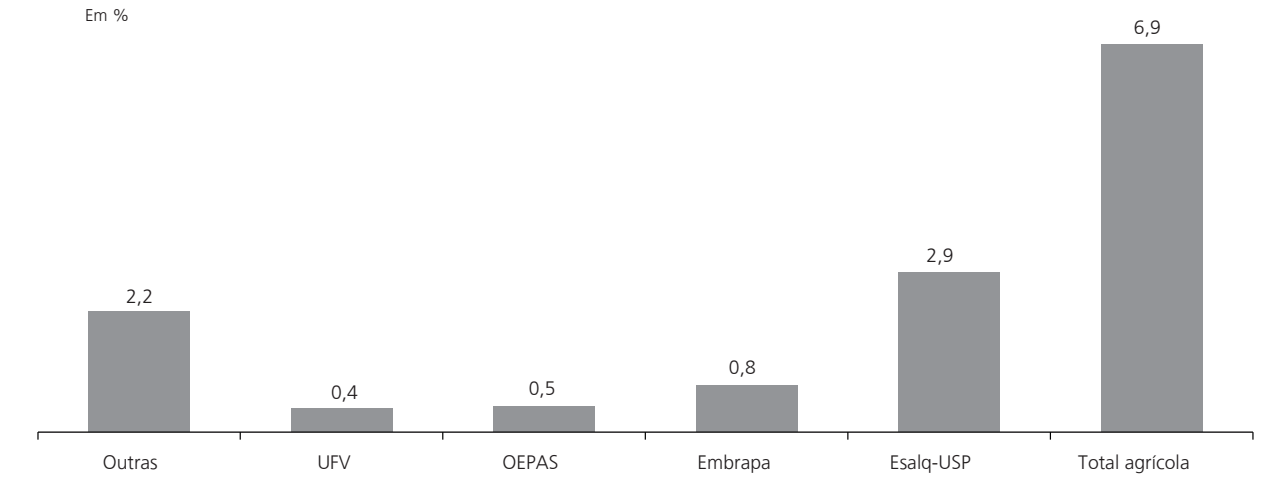

Fonte: Ministério da Ciência e Tecnologia (2009). Elaboração do autor. 


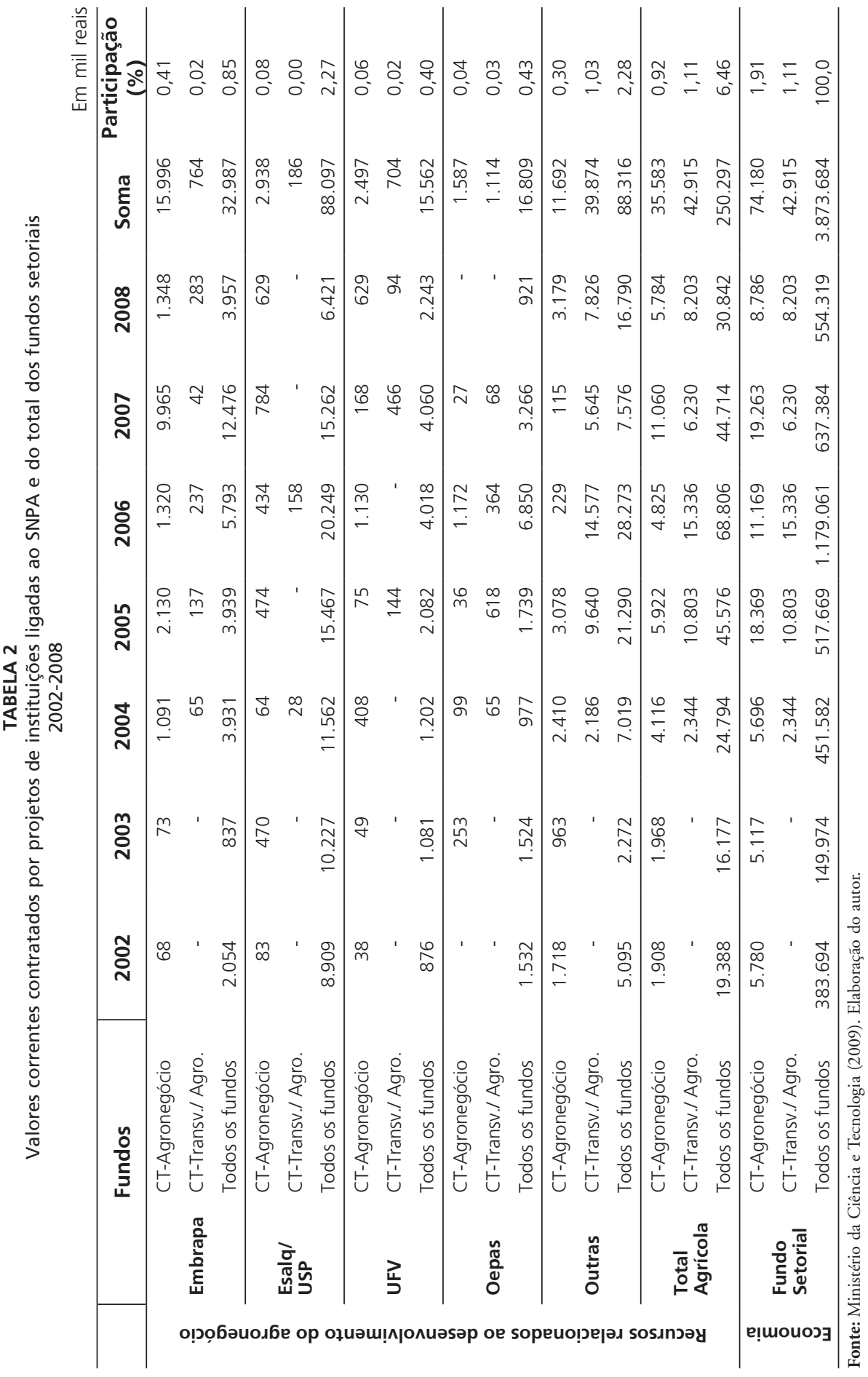


$\mathrm{Na}$ tentativa de identificar a interação entre o projeto de pesquisa e a instituição executora numa amostra dos fundos setoriais, tanto no CT-Agronegócio quanto no restante dos projetos relacionados ao agronegócio (excluído o CT-Agronegócio), procurou-se verificar qual percentual está associado às empresas ${ }^{11}$ executoras ou mesmo às universidades e aos institutos de pesquisas. ${ }^{12}$ Os dados do Gráfico 9 mostraram que, no agregado, a maioria das instituições executoras corresponde a universidades e institutos de pesquisas, o que é natural no desenvolvimento de tecnologias para a agricultura. Deve-se ressaltar que a tecnologia agrícola é considerada um bem público e, portanto, o desenvolvimento da ciência básica em conhecimento aplicado é, em sua maior parte, fomentado por instituições públicas, ao contrário do setor industrial. Quando analisado apenas o CT-Agronegócio, têm-se 6\% de empresas executoras, enquanto as universidades e institutos de pesquisas representam 36\%. Se o foco estiver no grupo de projetos relacionados à agricultura, exclusos os do CT-Agronegócio, as empresas possuem $9 \%$ e as universidades e institutos de pesquisas, $48 \%$.

Conclusão semelhante pode ser interpretada pela matriz de interações de subdomínio tecnológico versus área de conhecimento científico. Utiliza-se a matriz de interação para verificar o grau de associação entre as instituições financiadas (fundamentalmente, universidades e institutos de pesquisa) com as empresas. ${ }^{13}$ Tais matrizes associam os projetos dos fundos setoriais com as empresas financiadas e com os grupos de pesquisa do Diretório do Conselho Nacional de Desenvolvimento Científico e Tecnológico (CNPq), além de identificar a interação e o vínculo dos grupos com as empresas. Esta matriz cruza os dados dos projetos em sua aplicação industrial (setor tecnológico) e em sua área científica (ciência). De um lado, a matriz direta estuda as interações dos projetos e seus vínculos entre os vários setores industriais, sendo os projetos associados diretamente a uma empresa interveniente.

11 Essa classificação já pertence à base dos fundos setoriais e tem como referência a natureza jurídica e a Classificação Nacional de Atividade Econômica (CNAE) da empresa. Dada a natureza jurídica, a Embrapa está nessa categoria. A CNAE da Embrapa é 72, relativa à "Pesquisa e Desenvolvimento Científico". Há outros órgãos classificados como firmas com essa mesma CNAE (por exemplo, a NANOCORE Biotecnologia Ltda.). Não foi adotado nenhum critério especial para definir as empresas, apenas utilizou-se este critério para separar os institutos de pesquisas deste contexto.

12 São classificadas como fundações as empresas cuja natureza jurídica se define como "fundações"; as empresas com classe jurídica relacionada à "Pesquisa e Desenvolvimento Científico" (CNAE 72) e que não são firmas; e, por fim, as empresas com classe jurídica definida, que possuem "Universidade" no nome da instituição e que não são firmas. Vale lembrar que existem universidades particulares definidas como firmas. Por fim, qualquer empresa que não tenha classe jurídica não foi classificada, tanto para firmas quanto para universidades e institutos de pesquisas.

13 Para a metodologia de avaliação da interação entre os grupos e as empresas, ver Rapini (2007). 
Do outro, a matriz indireta capta a relação do projeto e o vínculo indireto com as empresas, dado que os institutos de pesquisa e/ou as universidades são os executores diretos dos programas de pesquisas. Todavia, há um vínculo por grupo temático entre as instituiçõos de pesquisa e as empresas.

\section{GRÁFICO 9}

Participação dos projetos por instituições executoras do CT-Agronegócio e do conjunto do setor agrícola 2002-2009

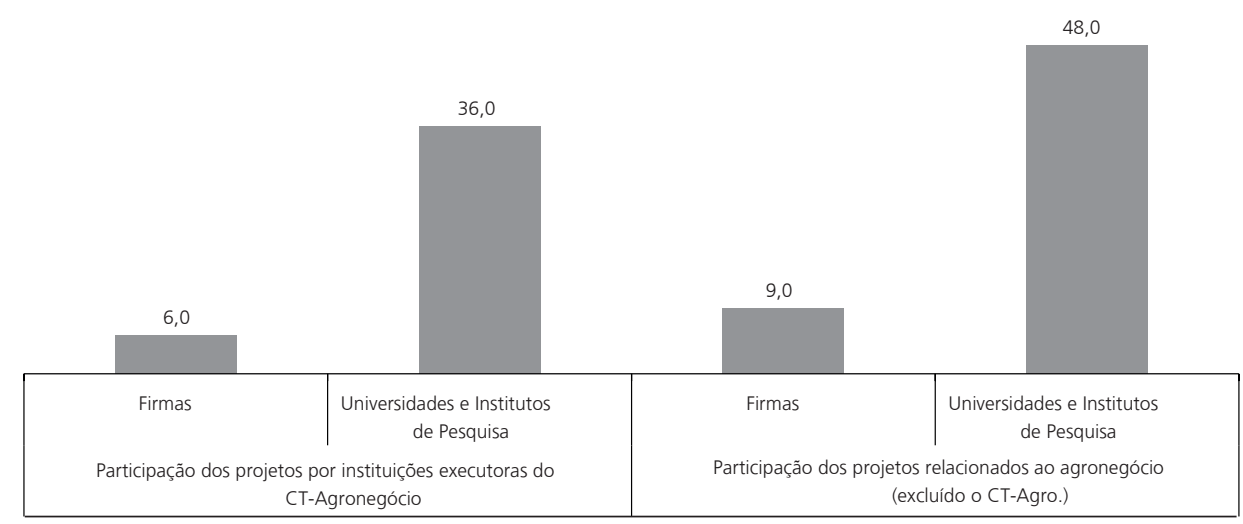

Fonte: Ministério da Ciência e Tecnologia (2009). Elaboração do autor.

Nota: Os percentuais aqui expostos podem estar sobrepostos, dado que pode existir mais de uma instituição na execução de cada projeto.

\section{GRÁFICO 10}

Matrizes de interações de subdomínio tecnológico e área de conhecimento científico para o CT-Agronegócio 2002-2008
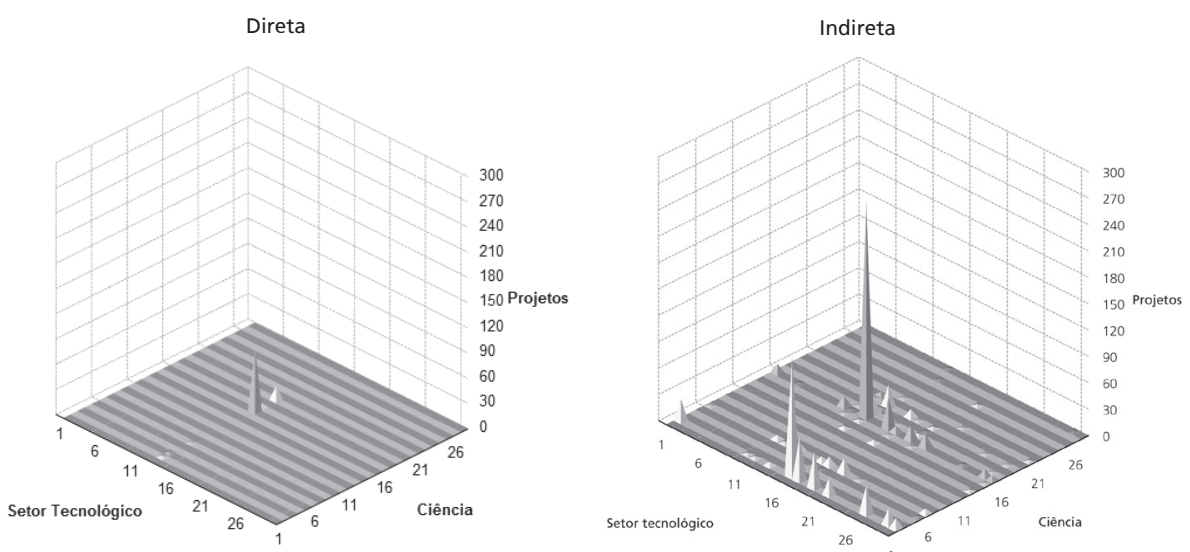

Fonte: Ministério da Ciência e Tecnologia (2009). Elaboração do autor. 
De acordo com o Gráfico 10, os picos de interaçôes dos projetos se dão de forma indireta com as empresas em sua grande maioria. Em relação à matriz de interações diretas, o setor tecnológico de "produtos agrícolas e alimentares" correlaciona-se com as áreas de "ciência dos alimentos e agricultura", assim como com "biologia geral". No que tange à matriz de interaçôes indiretas, há maior intensidade de picos, e os cruzamentos mais intensos são verificados entre o setor tecnológico de "produtos agrícolas e alimentares" e a "ciência dos alimentos e agricultura", o que era de se esperar já que o pico na matriz direta se coloca neste lugar. De qualquer forma, identifica-se outro pico que relaciona o setor tecnológico de "trabalho com materiais" junto com a "ciência dos materiais". Como conclusão geral desta análise matricial, nota-se uma baixa vinculação do CT-Agronegócio com as empresas. Porém, isso não significa que há baixo desenvolvimento tecnológico. Como já explicado, é o setor público o principal agente no provimento de tecnologias.

\section{Considerações finais}

O presente estudo procurou avaliar os fundos setoriais e as políticas públicas voltadas ao fomento da produção agropecuária de inovação tecnológica. De um lado, apresentou-se o quadro institucional que coordena todo o planejamento estratégico da pesquisa agrícola. De outro, verificou-se a representatividade dos fundos setoriais e a forma com que tais recursos favorecem a relação entre ciência e tecnologia.

A compreensão da dinâmica inovativa no setor agropecuário deve ser entendida por dois eixos. O primeiro diz respeito à organização do sistema no provimento de conhecimento público, o qual possa elevar os ganhos de produtividade. $\mathrm{O}$ segundo relaciona-se ao agente produtivo que visa o aumento de sua capacidade de absorção de conhecimentos externos. Nesse sentido, o ambiente institucional deve prover conhecimento adequado ao ganho produtivo do setor; porém, cabe ao produtor agropecuário realizar investimentos em sua capacitação, no intuito de decodificar e explorar melhor o conhecimento público.

A Embrapa, criada na década de 1970, definiu estratégias de planejamento da pesquisa agropecuária no Brasil, organizando as redes institucionais nas diferentes regiōes ao longo dos anos subsequentes. Com a criação do SNPA, no início dos anos 1990, diretrizes foram estabelecidas com a finalidade de constituir uma maior integração no sistema de inovação, a ponto de otimizar os recursos e evitar a sobreposição dos investimentos. Dentro deste contexto, em 2001, a criação dos fundos 
setoriais com a inclusão de um fundo específico ao agronegócio veio complementar os esforços realizados pelo governo no fortalecimento do setor.

Embora o empenho dos recursos do CT-Agronegócio seja pouco representativo no conjunto das despesas agrícolas, quando comparado à receita operacional líquida da Embrapa, sua representatividade é algo não desprezível, em torno de 6\%. Ademais, ao realizar o estudo amostral, entre 2002 e 2008, nota-se uma importante representatividade do setor agropecuário como um todo, sendo de $6,9 \%$ o percentual médio anual do valor contratado por instituiçóes de pesquisa do agronegócio. Vale destacar também que o agronegócio foi priorizado no conjunto das Ações Transversais, recebendo mais recursos do que colocando. Este fato mostra a importância do setor agropecuário para a economia em geral.

Todavia, é necessário fazer algumas observações em relação à vulnerabilidade do setor agropecuário e das políticas públicas de fomento à pesquisa e à inovação tecnológica. Em primeiro lugar, é importante ressaltar a dependência nacional da importação de insumos tecnológicos (sejam defensivos, medicamentos veterinários e fertilizantes). Diante da incapacidade de uma produção doméstica mais consolidada, espera-se que as políticas de ciência e tecnologia aumentem o conhecimento codificado (ampliando as oportunidades tecnológicas em diferentes domínios de pesquisa científica), como também estimulem as aplicaçōes industriais do novo conhecimento.

De acordo com as aplicações dos fundos setoriais, a execução dos projetos é em grande parte realizada por universidades e instituiçôes de pesquisa, o que é um indicativo da importância do ambiente institucional no provimento de novas tecnologias aplicadas ao segmento produtivo. Espera-se, portanto, embora reconhecendo os fundos setoriais como um mecanismo complementar de apoio à ciência e tecnologia, que haja um melhor planejamento por parte do governo para o desenvolvimento científico e tecnológico. Como a criação destes fundos ainda é muito recente, há espaço para se pensar e melhor alocar os recursos, buscando sempre o crescimento produtivo do setor agropecuário.

\section{Referências bibliográficas}

BRESCHI, S.; MALERBA, F.; ORSENIGO, L. Technological regimes and schumpeterian patterns of innovation. The Economic Journal, v. 110, p. 388-410, Apr. 2000.

DOSI, G. Technical change and industrial transformation. New York: St. Martin's Press, 1984. 
- Technological paradigms and technological trajectories: a suggested interpretation of the determinants and directions of technical change. Research Policy, v. 11, p. 147-162, 1982.

EMBRAPA - Empresa Brasileira de Pesquisa Agropecuária. Balanço social. Brasília, 2009.

GASQUES, J. G. et al. Desempenho e crescimento do agronegócio no Brasil. Brasília: Ipea, 2004 (Texto para discussão, n. 1.009).

HADDAD, P. R. Medidas de localização e de especialização. In: HADDAD, P. R. et al. Economia regional: teorias e métodos de análise. Fortaleza: Banco do Nordeste, 1989, p. 225-245.

IBGE - Instituto Brasileiro de Geografia e Estatística. Pesquisa Industrial de Inovação Tecnológica (tabulações especiais - 2000, 2003 e 2005). Rio de Janeiro, 2009.

MALERBA, F; ORSENIGO, L. Schumpeterian patterns of innovation are technologyspecific. Research Policy, v. 25, p .451-478, 1996.

MINISTÉRIO DA CIÊNCIA E TECNOLOGIA - MCT. Fundos setoriais (tabulações especiais). Brasília, 2009.

MINISTÉRIO DO DESENVOLVIMENTO, INDÚSTRIA E COMÉRCIO EXTERIOR - MDIC. Sistema Alice/Secex (tabulações especiais). Brasília, 2009.

POSSAS, M. L.; SALLES-FILHO, S.; SILVEIRA, J. M. da. An evolutionary approach to technological innovation in agriculture: some preliminary remarks. Research Policy, v. 25, p. 933-945, Feb. 1996.

RAPINI, M. S. Interação universidade-empresa no Brasil: evidências do diretório dos grupos de pesquisa do CNPq. Estudos Econômicos, v. 37, n. 1, p. 211-233, 2007.

VIEIRA FILHO, J. E. R. Abordagem evolucionária da dinâmica do setor agrícola. Dissertação (Mestrado) - Universidade Federal de Viçosa, Viçosa, 2004.

Inovação tecnológica e aprendizado agrícola: uma abordagem schumpeteriana.

Tese (Doutorado em Teoria Econômica) - Universidade de Campinas, Campinas, 2009.

VIEIRA FILHO, J. E. R.; CAMPOS, A. C.; FERREIRA, C. M. de C. Abordagem alternativa do crescimento agrícola: um modelo de dinâmica evolucionária. Revista Brasileira de Inovação, v. 4, n. 2, p. 425-476, jul./dez. 2005. 


\section{ANEXO}

Agregação utilizada por meio da CNAE para subdividir os setores relacionados ao agronegócio entre insumos tecnológicos e indústria de transformação

\begin{tabular}{|c|c|c|c|}
\hline CNAE & Nomenclatura & $\begin{array}{l}\text { Setores } \\
\text { agregados }\end{array}$ & $\begin{array}{l}\text { Subdi- } \\
\text { visão }\end{array}$ \\
\hline $1421-4$ & $\begin{array}{l}\text { - Extração de minerais para fabricação de } \\
\text { adubos, fertilizantes e produtos químicos }\end{array}$ & $\begin{array}{l}\text { Indústria extrativa } \\
\text { mineral }\end{array}$ & \multirow{12}{*}{ 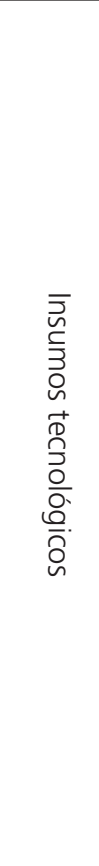 } \\
\hline $1556-3$ & $\begin{array}{l}\text { - Fabricação de rações balanceadas para } \\
\text { animais }\end{array}$ & Rações & \\
\hline $2412-0$ & $\begin{array}{l}\text { - Fabricação de intermediários para } \\
\text { fertilizantes }\end{array}$ & & \\
\hline 2413-9 & $\begin{array}{l}\text { - Fabricação de fertilizantes fosfatados, } \\
\text { nitrogenados e potássicos }\end{array}$ & Fertilıantes & \\
\hline $2453-8$ & $\begin{array}{l}\text { - Fabricação de medicamentos para uso } \\
\text { veterinário }\end{array}$ & $\begin{array}{l}\text { Medicamentos } \\
\text { veterinários }\end{array}$ & \\
\hline $2461-9$ & - Fabricação de inseticidas & \multirow{4}{*}{ Defensivos } & \\
\hline $2462-7$ & - Fabricação de fungicidas & & \\
\hline $2463-5$ & - Fabricação de herbicidas & & \\
\hline $2469-4$ & - Fabricação de outros defensivos agrícolas & & \\
\hline $2692-1$ & $\begin{array}{l}\text { - Fabricação de cal virgem, cal hidratada e } \\
\text { gesso }\end{array}$ & Calcário & \\
\hline $2931-9$ & $\begin{array}{l}\text { - Fabricação de máquinas e equipamentos } \\
\text { para agricultura, avicultura e obtenção de } \\
\text { produtos animais }\end{array}$ & \multirow[t]{2}{*}{$\begin{array}{l}\text { Máquinas e } \\
\text { tratores }\end{array}$} & \\
\hline $2932-7$ & - Fabricação de tratores agrícolas & & \\
\hline 151 & $\begin{array}{l}\text { - Abate e preparação de produtos de carne e } \\
\text { de pescado }\end{array}$ & \multirow{8}{*}{$\begin{array}{l}\text { Indústria de } \\
\text { transformação }\end{array}$} & \multirow{9}{*}{ 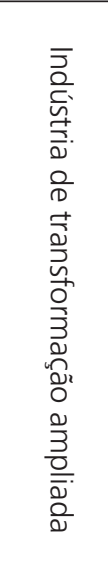 } \\
\hline 152 & $\begin{array}{l}\text { - Processamento, preservação e produção } \\
\text { de conservas de frutas, legumes e outros } \\
\text { vegetais }\end{array}$ & & \\
\hline 153 & $\begin{array}{l}\text { - Produção de óleos e gorduras vegetais e } \\
\text { animais }\end{array}$ & & \\
\hline 154 & - Laticínios & & \\
\hline 156 & - Fabricação e refino de açúcar & & \\
\hline 157 & - Torrefação e moagem de café & & \\
\hline 159 & - Fabricação de bebidas & & \\
\hline 171 & - Beneficiamento de fibras têxteis naturais & & \\
\hline 234 & - Produção de álcool & Biocombustível & \\
\hline
\end{tabular}

Fonte: Elaboração do autor. 
José Eustáquio Ribeiro Vieira Filho

ENDEREÇO PARA CORRESPONDENCIA

José Eustáquio Ribeiro Vieira Filho - jose.vieira@ipea.gov.br Ipea - Instituto de Pesquisa Econômica Aplicada SBS - Quadra 1, bloco J, Ed. BNDES, sala 1108 70076-900 - Brasília (DF), Brasil 